\title{
Review Article \\ Potential Roles of Amiloride-Sensitive Sodium Channels in Cancer Development
}

\author{
Siguang $\mathrm{Xu},{ }^{1,2}$ Cui Liu, ${ }^{2}$ Yana $\mathrm{Ma}^{1}$ Hong-Long $\mathrm{Ji}^{1,3,4}$ and Xiumin $\mathrm{Li}^{2}$ \\ ${ }^{1}$ Institute of Lung and Molecular Therapy, Xinxiang Medical University, Xinxiang, Henan 453003, China \\ ${ }^{2}$ Center for Cancer Research, Xinxiang Medical University, Xinxiang, Henan 453003, China \\ ${ }^{3}$ Department of Cellular and Molecular Biology, University of Texas Health Science Center at Tyler, Tyler, TX 75708, USA \\ ${ }^{4}$ Texas Lung Injury Institute, University of Texas Health Science Center at Tyler, Tyler, TX 75708, USA
}

Correspondence should be addressed to Xiumin Li; 1xm3029981@126.com

Received 28 January 2016; Revised 18 April 2016; Accepted 23 May 2016

Academic Editor: Stephan M. Huber

Copyright (c) 2016 Siguang Xu et al. This is an open access article distributed under the Creative Commons Attribution License, which permits unrestricted use, distribution, and reproduction in any medium, provided the original work is properly cited.

\begin{abstract}
The ENaC/degenerin ion channel superfamily includes the amiloride-sensitive epithelial sodium channel (ENaC) and acid sensitive ionic channel (ASIC). ENaC is a multimeric ion channel formed by heteromultimeric membrane glycoproteins, which participate in a multitude of biological processes by mediating the transport of sodium $\left(\mathrm{Na}^{+}\right)$across epithelial tissues such as the kidney, lungs, bladder, and gut. Aberrant $\mathrm{ENaC}$ functions contribute to several human disease states including pseudohypoaldosteronism, Liddle syndrome, cystic fibrosis, and salt-sensitive hypertension. Increasing evidence suggests that ion channels not only regulate ion homeostasis and electric signaling in excitable cells but also play important roles in cancer cell behaviors such as proliferation, apoptosis, invasion, and migration. Indeed, ENaCs/ASICs had been reported to be associated with cancer characteristics. Given their cell surface localization and pharmacology, pharmacological strategies to target ENaC/ASIC family members may be promising cancer therapeutics.
\end{abstract}

\section{Introduction}

Cancer is one of the leading causes of death worldwide. As reported by the World Health Organization, approximately 14 million new cancer cases were diagnosed in 2012, and 8.2 million deaths were cancer related. Of even greater concern, it is estimated that annual cancer cases will increase from 14 million in 2012 to 22 million within the next two decades. Although the traditional clinical treatments for cancer, including surgery, chemotherapy, and radiation therapy, have shown efficacy, side effects significantly reduce the quality of life for patients. Cancer relapse and treatment resistance further underscore the urgent need to identify novel targets for alternative therapies.

Ion channels are transmembrane proteins that have long been known to be involved in regulating a variety of physiological and pathological functions across biological membranes. Currently, approximately $13 \%$ of drugs used to treat various human diseases, including cardiovascular and neurological disorders, primarily target ion channels [1].
Indeed, the term channelopathies was coined to describe the ever growing number of diseases associated with ion channel function $[2,3]$. Although cancer is still not cataloged as a channelopathy because of its complexity, it can be ascribed, at least in part, to ion channel malfunction [4]. An increasing number of studies showed that $\mathrm{ENaC}$ and ASIC channels are involved in various cancer cell behaviors, such as proliferation, apoptosis, invasion, and migration, and suggest that these channels are potential therapeutic targets for personalized cancer treatment $[2,4]$. In this review, we summarize the latest findings on the role of $\mathrm{ENaC}$ and ASIC channels in cancer and discuss the mechanisms by which $\mathrm{ENaC}$ and $\mathrm{ASIC}$ channels may regulate cancer behaviors.

\section{ENaC and ASIC in Proliferation and Apoptosis}

Cell division and proliferation are key processes in cancer development and a role for ion channels in mediating cell 
proliferation has been reported in multiple types of cancer [4]. Indeed, earlier studies have shown that an influx of sodium ions $\left(\mathrm{Na}^{+}\right)$may stimulate a mitogenic signal and initiate the cell cycle and that inhibition of sodium transport can reduce the DNA synthesis required for cell proliferation $[5,6]$. The role of the $\alpha$-ENaC subunit in cell proliferation was first reported by Bondarava et al. [7], who showed that silencing $\alpha$-ENaC reduced hypertonicity-induced $\mathrm{Na}^{+}$currents by $60 \%$ and that HepG2 cell proliferation correspondingly decreased to approximately half that of the control. Moreover, transfection with $\alpha$-ENaC siRNA caused a significant decrease in G1 phase cells and an increase in G2/M phase cells; the rate of apoptosis of HepG2 cells was also increased possibly because $\alpha$-ENaC siRNA reduced $\mathrm{Na}^{+}$currents, with the subsequent cell shrinkage (termed apoptotic volume decrease) being a hallmark of early apoptosis [8-10]. These results also revealed that $\alpha$-ENaC plays a role in regulating $\mathrm{Na}^{+}$-induced cell proliferation, that its expression may be involved in tumor growth, and that it is a promising target for cancer treatment. Interestingly, although the sequence of $\alpha$-ENaC has $35 \%$ homology at the amino acid level with $\gamma$-ENaC [11], Wang et al. [12] showed that inhibition of $\gamma$-ENaC is a possible mechanism for the antiapoptotic effects of hypotonic stress on IMCD cells, with p38, JNK, ERK, and the EGFR-JNK$\mathrm{PI} 3 \mathrm{~K}$ pathway potentially stimulating sodium reabsorption in response to hypotonic stress via regulation of $\gamma$-ENaC [1315]. Indeed, subcellular distribution of $\mathrm{ENaC}$ subunits varies: $\alpha$-ENaC tends to be presented at the apical membrane of principal cells, whereas $\beta$-ENaC and $\gamma$-ENaC are dispersed throughout the entire cytoplasm. Whether these diverse distributions are involved in cancer development is unknown [16]. Although $\delta$-ENaC shared 37\% homology with $\alpha$-ENaC and can form channels alone, or in combination with $\beta$ $\mathrm{ENaC}$ and $\gamma$-ENaC [17], Rooj et al. reported that knocking down $\delta$-ENaC had no effect on cyclin-dependent kinase inhibitor expression in glioma [18]. In addition, serum- and glucocorticoid-regulated kinase 1 , as a downstream effector of antiapoptotic phosphoinositide 3-kinase signaling, may interact with $\mathrm{ENaC}$ and specifically enhance $\mathrm{ENaC}$ activity [19]. In this process, glucocorticoid-induced leucine zipper 1 may help serum- and glucocorticoid-regulated kinase 1 to recruit ENaC by regulating the stability and localization of serum- and glucocorticoid-regulated kinase 1 [20]. Thus, understanding the role of $\mathrm{ENaC}$ family in proliferation and tumor growth requires further studies.

In addition to ENaCs, ASICs also belong to the epithelial/sodium channel degenerin (ENaC/DEG) superfamily and are predominantly distributed within the central and peripheral nervous systems [21]. Indeed, there is increasing evidence that ASICs are associated with malignant gliomas and that high-grade gliomas, such as glioblastoma multiforme, express multiple members of the ENaC/DEG family and characteristically display an amiloride-sensitive cation current, which is not seen in lower-grade gliomas or normal human astrocytes [22]. The malignant behavior, including high rates of proliferation, exhibited by glioma cells also requires large changes in cell volume, and volume recovery is important for a tumor cell $[23,24]$. The spider toxin PcTx1, a selective ASIC1 blocker, inhibits ASIC1 but has no effect on

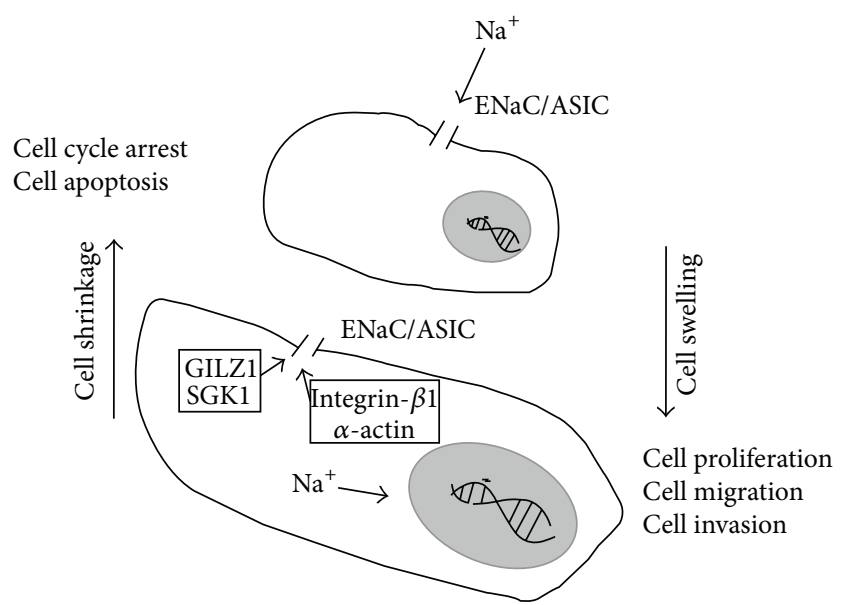

FIgUre 1: Contribution of ENaC/ASIC mediating $\mathrm{Na}^{+}$current to cell volume in cancer cell development. ENaC/ASIC mediating $\mathrm{Na}^{+}$ influx promoted the proliferation, migration, and invasion of cancer cell, compared to blockage of this $\mathrm{Na}^{+}$influx inducing cell cycle arrest and apoptosis of cancer cell.

other members of the ENaC/DEG family (tested mostly on homomeric channels) [18]. Both PcTX-1 and benzamil, an amiloride analog, induced cell cycle arrest of glioma D54MG cells in G0/G1 phases, reduced cell accumulation in the S and G2/M phases, and upregulated the expression of the cell cycle inhibitors p21Cip1 and p27Kip1 [18]. Similar results were found with ASIC1 knockdowns, using U87MG and primary glioblastoma multiforme cells maintained in primary culture [18], and may be due to the effect of the ASIC1 knockdown on cell volume recovery via cation currents, because cells cannot divide in a shrunken state. Hu et al. further reported that blocking ASICs inhibited acid-induced apoptotic effect in chondrocytes in vitro, probably by inhibiting $\mathrm{Ca}^{2+}$ influx [25], as increased intracellular free $\mathrm{Ca}^{2+}$ is known to be involved in the development of apoptosis [26-29]. These results potentially explain the molecular mechanisms by which ASICs regulate the growth and apoptosis of cells.

\section{ENaC and ASIC in Migration and Invasion}

Cancer cell migration and invasion are additional malignant behaviors in the progression of cancer. The ability of cancer cells to migrate allows them to metastasize in the body and invade other tissues or organs [30]. This process required the cell to become polarized and change its shape or stiffness, such as forming the lamellipodium and developing similar invadopodia, so that the cell can attach to the extracellular matrix and explore the surroundings via cell swelling, or retract the rear end of the cell via cell shrinking (Figure 1) [4]. These cell volume changes are normally regulated by ion transportation through various ion channels [31]. Malignant melanoma is the most aggressive neoplasm with severe metastatic potential and four homologous $\mathrm{ENaC}$ subunits $\left(\alpha-, \beta-, \gamma^{-}\right.$, and $\left.\delta_{-}\right)$were reported to be expressed in human malignant melanoma cells [32], but their relevance in malignancy and detailed function in malignant melanoma 
were unknown. Del Mónaco et al. further reported that they used antisense oligonucleotides directed against the $\alpha$-ENaC subunit to decrease the migratory ability of BeWo cells [33], and Marino et al. further reported that aldosterone increased the ability of wound healing in BeWo cells in part through methylation of the $\mathrm{ENaC}$ [34]. Upregulation of $\alpha$-ENaC can also stimulate trophoblast cell invasion ability by promoting the expression of matrix metalloproteinase 2, and knocking down $\alpha$-ENaC expression reduces the invasion and migration abilities of HTR-8/SVneo cells $[35,36]$. Additionally, induction of $\beta$-ENaC expression by heme oxygenase- 1 promotes cytotrophoblast migration [37]. A recent study reported that $\alpha$-ENaC and $\gamma$-ENaC were highly expressed in D54MG human glioblastoma multiforme cells, compared with primary human astrocytes [38]. Additionally, knocking down $\alpha$-ENaC or $\gamma$-ENaC affected the high $\mathrm{P}_{\mathrm{K}}{ }^{+} / \mathrm{P}_{\mathrm{Na}}{ }^{+}$of D54-MG cells, and knocking down $\alpha$-ENaC or $\gamma$-ENaC significantly inhibited D54-MG cell migration [38]. The inhibition of $\mathrm{Na}^{+}$ influx after channel knockdown and the subsequent inhibition of cell swelling required for lamellipodium expansion may be responsible for these observations. Furthermore, the established sodium gradient allows cells to take in important metabolic substrates and remove harmful metabolites and transportation of $\mathrm{Na}^{+}$across the plasma membrane also enables cells to control their internal volume, including swelling or shrinkage [4]. Other studies have demonstrated that the subunits of $\alpha-\mathrm{ENaC}$ and $\gamma$-ENaC regulated the cation current, including $\mathrm{Na}^{+}$, playing an essential biological function in glioma cell migration and invasion $[23,24,39-$ 44]. Tumor cells may use cation currents to recover volume, following migration through the brain parenchyma, and to move through the narrow extracellular spaces in the brain. Rooj et al. further reported physical and functional interactions between integrin- $\beta 1$ and the amiloride-sensitive nonselective cation channel, composed of ASIC1, $\alpha$-ENaC, and $\gamma$-ENaC, and further showed that knockdown of either integrin- $\beta 1$ or $\alpha$-actinin attenuated the amiloride-sensitive current [45], indicating that integrin- $\beta 1$ and $\alpha$-actinin may be involved in stabilizing the glioma cation channel complex and maintaining channel activity.

ASIC1 subunits also function similarly in promoting cancer cell migration. Sun et al. reported that CaMKII interacts with ASICl and colocalizes at the plasma membrane to form a functional complex that regulates glioma cell migration [46]. Here, the ASICl current plays an important role in glioma cell migration ability $[18,38]$, cell cycle progression [18], and volume regulation [47]. The $\mathrm{Ca}^{2+}$-sensitive kinase CaMKII may also play an important role in glioma biology by catalyzing the phosphorylation of ASICla at residues Ser478 and Ser479 and subsequently activating the ASIC channels [48]. Moreover, $\mathrm{Ca}^{2+}$ acts as a second messenger for supporting glioma cell migration [49], and ASICla may be permeable to calcium [50], suggesting that activated ASIC1 channels allow calcium to permeate and activate CaMKII, thereby regulating ASIC1 channels. In hepatocellular cancers, ASICl $\alpha$ is also highly expressed and associated with advanced clinical stage. A moderately acidic extracellular environment can promote ASICl $\alpha$ expression, and the migration and invasion of hepatocellular cells can be inhibited by silencing of ASIC1 $\alpha$ expression [51], supporting evidence that tissue acidosis, an important feature of tumorigenesis, is associated with cancer invasion and angiogenesis [52]. In fact, many tumors showed a lower extracellular $\mathrm{pH}(\mathrm{pHe})$ environment compared with the corresponding normal tissue [53]. Rapid exposure of tumor cells to an acidic environment can transiently upregulate the proteolytic enzymes MMP-2 and MMP-9 and the proangiogenic factors IL-8 and VEGF-A [53, $54]$ and can also activate ASICs and induce $\mathrm{Na}^{+}$influx, which subsequently affects cell volume regulation and membrane potential $[55,56]$, revealing that ASICs may be involved in regulating this process in cancer.

Nevertheless, not all ASIC family members play the same role in cancer. The amiloride-sensitive inward $\mathrm{Na}^{+}$current, found in gliomas (also called glioblastoma multiforme or GBM), is absent in normal astrocytes and low-grade gliomas. Some studies show that GBM cells express this basal current due to the lack of ASIC2 in the plasma membrane [57]. Furthermore, although ASIC2a and ASIC3 are highly expressed in adenoid cystic carcinoma [58], surface expression of ASIC2 abolished the amiloride-sensitive inward $\mathrm{Na}^{+}$current and promoted a reversion of a high-grade glioma cell to a more normal (i.e., nonmalignant) astrocytic phenotype [39]. Similar studies further reported that interaction between Hsc70 and ASIC2 can increase retention of ASIC2 in the endoplasmic reticulum in cells but that silencing Hsc70 may abolish the interaction, increase the surface expression of ASIC2 on cells, and inhibit cell migration, thereby also promoting reversion of a high-grade glioma cell to a more normal astrocytic phenotype $[57,59]$. However, Liu et al. reported that knockdown of ASIC2a could increase the acidosis-induced cytotoxicity via the intracellular calcium overload in C6 glioma cells, revealing that ASIC2a could change the properties of ASICs, such as acid sensitivity and $\mathrm{Ca}^{2+}$ permeability, and subsequently affect the invasion and migration of the cells. Therefore, in contrast to ASICla, ASIC2a may play a protective role against the injury induced by extracellular acidosis in C6 cells [60]. Further investigation is needed to characterize more fully the role of each member of the ASIC family in cancer.

\section{Prospective Studies}

Studies on the role of other (ENaC/DEG) family members, such as HyNaC, DEL, PPK, UNC, and ACD [61], in cancer development have rarely been reported. However, increasing evidence suggests that ENaCs and ASICs of the ENaC/DEG family are associated with key aspects of cancer, and targeting members of this family is a potentially viable therapeutic approach. For example, recent study indicates that the acidic microenvironment (low extracellular $\mathrm{pH}$, i.e., pHeacidosis) can enhance the invasion activity of breast cancer cells in a ROS-AKT-NF- $\kappa$ B-dependent manner. During this process, ASIC1 is required for acidosis-induced reactive oxidative species (ROS) production and NF- $\kappa \mathrm{B}$ activation, two key events for tumorigenesis. Moreover, regulation of ROS production by ASIC1 is specific to acidosis-induced cell invasion and tumor growth [62]. These data make ASIC1 
an attractive target in breast cancer. On the other hand, most $\mathrm{ENaC} / \mathrm{ASIC}$ proteins share a highly conserved structure: intracellular $\mathrm{N}$ - and C-termini and two membrane-spanning domains separated by a large extracellular domain [17]. Particularly, the pre-M2 region shows high homology between $\mathrm{ENaC}$ and ASIC. ENaC and ASIC both form amiloridesensitive, non-voltage gated cation channels. ASIC channels tend to require higher doses of amiloride than ENaC. In addition, ASIC proteins (ASIC1, ASIC2, ASIC3, and ASIC4) can also form homo- and heteromultimeric channels that generally conduct $\mathrm{Na}^{+}$, although ASICs are activated by protons $\left(\mathrm{H}^{+}\right)$and ENaCs are highly selective for $\mathrm{Na}^{+}$and $\mathrm{Li}^{+}$[17]. All the common properties implicated that ENaC may play important roles in cancer development as ASIC did. Indeed, $\gamma$-ENaC was also reported to mediate ROS release in breast cancer [63], thus suggesting that targeting $\mathrm{ENaC}$ is also attractive in breast cancer. Tumor cells can use various mechanisms to remove intracellular acids to maintain physiological intracellular $\mathrm{pH}$. These mechanisms include $\mathrm{Na}$-driven proton extrusion, $\mathrm{Na}^{+} / \mathrm{H}^{+}$exchangers. As a result, extracellular $\mathrm{pH}$ becomes more acidic. Acidity is harmful to normal cell, but tumor cells adapted well to acidic microenvironment during a long time of coevolution with the host [64]. ENaC/ASIC-mediated regulation of $\mathrm{Na}^{+}$ influx and reactive oxidative species (ROS) product may be involved in the sensing of external acidosis by tumor cells and downstream cascade. In addition, alterations of five ASIC genes were significantly related to poor patient survival [62]. To find out the mechanism of ASIC2, ASIC3, ASIC4, and ASIC5 on cancer development will be a specific question for next investigation. Particularly, ASIC5 is primarily expressed in the small intestine and the function of ASIC5 is not known [65]. Other significant questions also need to be addressed. Firstly, do factors in the tumor microenvironment, such as inflammation, immune cells, irradiation, chemotherapy treatment, or specific metabolins, induce activity of differential ENaC/DEG family members that can confer drug resistance? Secondly, are any mutations of ENaC/DEG family members involved in the oncogenic process and if so, are these mutated proteins potential targets for personalized medicine? Thirdly, can we use mutation of ENaC/DEG family members to establish various genetic models, for example, in the fruit fly, zebrafish, or mouse, to screen novel drug compounds that treat human cancer or other diseases? Fourthly, are there any drugs that when combined with ENaC/DEG family member inhibitors produce a synergistic effect in cancer therapy? Finally, are there any other novel proteins that can directly interact with and modify the function of ENaC/DEG family members during cancer development? Future research to address these and other questions will greatly enhance our understanding of the significance of the ENaC/DEG family in cancer and provide new avenues for the development of better therapies.

\section{Competing Interests}

The authors declare that there is no conflict of interests regarding the publication of this paper.

\section{References}

[1] J. P. Overington, B. Al-Lazikani, and A. L. Hopkins, "How many drug targets are there?" Nature Reviews Drug Discovery, vol. 5, no. 12, pp. 993-996, 2006.

[2] I. Restrepo-Angulo, A. De Vizcaya-Ruiz, and J. Camacho, "Ion channels in toxicology," Journal of Applied Toxicology, vol. 30, no. 6, pp. 497-512, 2010.

[3] O. Campuzano, C. Allegue, A. Fernandez, A. Iglesias, and R. Brugada, "Determining the pathogenicity of genetic variants associated with cardiac channelopathies," Scientific Reports, vol. 5, article 7953, 2015.

[4] A. Litan and S. A. Langhans, "Cancer as a channelopathy: ion channels and pumps in tumor development and progression," Frontiers in Cellular Neuroscience, vol. 9, article 86, 2015.

[5] M. E. O’Donnell, E. Cragoe Jr., and M. L. Villereal, "Inhibition of $\mathrm{Na}+$ influx and DNA synthesis in human fibroblasts and neuroblastoma-glioma hybrid cells by amiloride analogs," Journal of Pharmacology and Experimental Therapeutics, vol. 226, no. 2, pp. 368-372, 1983.

[6] M. E. O’Donnell and M. L. Villereal, “Membrane potential and sodium flux in neuroblastoma X glioma hybrid cells: effects of amiloride and serum," Journal of Cellular Physiology, vol. 113, no. 3, pp. 405-412, 1982.

[7] M. Bondarava, T. Li, E. Endl, and F. Wehner, " $\alpha$-ENaC is a functional element of the hypertonicity-induced cation channel in HepG2 cells and it mediates proliferation," Pflugers Archiv European Journal of Physiology, vol. 458, no. 4, pp. 675-687, 2009.

[8] J. F. Kerr, A. H. Wyllie, and A. R. Currie, "Apoptosis: a basic biological phenomenon with wide-ranging implications in tissue kinetics," British Journal of Cancer, vol. 26, no. 4, pp. 239257, 1972.

[9] A. H. Wyllie, "Glucocorticoid-induced thymocyte apoptosis is associated with endogenous endonuclease activation," Nature, vol. 284, no. 5756, pp. 555-556, 1980.

[10] C. D. Bortner and J. A. Cidlowski, "Cell shrinkage and monovalent cation fluxes: role in apoptosis," Archives of Biochemistry and Biophysics, vol. 462, no. 2, pp. 176-188, 2007.

[11] C. M. Canessa, L. Schild, G. Buell et al., "Amiloride-sensitive epithelial $\mathrm{Na}^{+}$channel is made of three homologous subunits," Nature, vol. 367, no. 6462, pp. 463-467, 1994.

[12] L. Wang, Y. Liu, H. Wang et al., "Epoxyeicosatrienoic acids attenuating hypotonic-induced apoptosis of IMCD cells via $\gamma$ ENaC inhibition," PLoS ONE, vol. 9, no. 4, Article ID e94400, 2014.

[13] N. Niisato, A. Taruno, and Y. Marunaka, "Involvement of p38 MAPK in hypotonic stress-induced stimulation of $\beta$ - and $\gamma$ ENaC expression in renal epithelium," Biochemical and Biophysical Research Communications, vol. 358, no. 3, pp. 819-824, 2007.

[14] A. Taruno, N. Niisato, and Y. Marunaka, "Hypotonicity stimulates renal epithelial sodium transport by activating JNK via receptor tyrosine kinases," American Journal of PhysiologyRenal Physiology, vol. 293, no. 1, pp. F128-F138, 2007.

[15] N. Niisato, M. Ohta, D. C. Eaton, and Y. Marunaka, "Hypotonic stress upregulates $\beta$ - and $\gamma$-ENaC expression through suppression of ERK by inducing MKP-1," American Journal of Physiology-Renal Physiology, vol. 303, no. 2, pp. F240-F252, 2012.

[16] H. Hager, T.-H. Kwon, A. K. Vinnikova et al., "Immunocytochemical and immunoelectron microscopic localization of 
$\alpha-, \beta$-, and $\gamma$-ENaC in rat kidney," American Journal of Physiology-Renal Physiology, vol. 280, no. 6, pp. F1093-F1106, 2001.

[17] S. Kellenberger and L. Schild, "Epithelial sodium channel/ degenerin family of ion channels: a variety of functions for a shared structure," Physiological Reviews, vol. 82, no. 3, pp. 735767, 2002.

[18] A. K. Rooj, C. M. McNicholas, R. Bartoszewski, Z. Bebok, D. J. Benos, and C. M. Fuller, "Glioma-specific cation conductance regulates migration and cell cycle progression," The Journal of Biological Chemistry, vol. 287, no. 6, pp. 4053-4065, 2012.

[19] S. V. Thomas, P. P. Kathpalia, M. Rajagopal et al., "Epithelial sodium channel regulation by cell surface-associated serumand glucocorticoid-regulated kinase 1," Journal of Biological Chemistry, vol. 286, no. 37, pp. 32074-32085, 2011.

[20] R. Soundararajan, J. Wang, D. Melters, and D. Pearce, "Glucocorticoid-induced leucine zipper 1 stimulates the epithelial sodium channel by regulating serum- and glucocorticoidinduced kinase 1 stability and subcellular localization," The Journal of Biological Chemistry, vol. 285, no. 51, pp. 39905-39913, 2010.

[21] D. A. De La Rosa, P. Zhang, D. Shao, F. White, and C. M. Canessa, "Functional implications of the localization and activity of acid-sensitive channels in rat peripheral nervous system," Proceedings of the National Academy of Sciences of the United States of America, vol. 99, no. 4, pp. 2326-2331, 2002.

[22] B. K. Berdiev, J. Xia, L. A. McLean et al., "Acid-sensing ion channels in malignant gliomas," Journal of Biological Chemistry, vol. 278, no. 17, pp. 15023-15034, 2003.

[23] K. Kunzelmann, "Ion channels and cancer," Journal of Membrane Biology, vol. 205, no. 3, pp. 159-173, 2005.

[24] H. Sontheimer, "Ion channels and amino acid transporters support the growth and invasion of primary brain tumors," Molecular Neurobiology, vol. 29, no. 1, pp. 61-71, 2004.

[25] W. Hu, F.-H. Chen, F.-L. Yuan et al., "Blockade of acid-sensing ion channels protects articular chondrocytes from acid-induced apoptotic injury," Inflammation Research, vol. 61, no. 4, pp. 327335, 2012.

[26] S. Jiang, S. C. Chow, P. Nicotera, and S. Orrenius, "Intracellular $\mathrm{Ca}^{2+}$ signals activate apoptosis in thymocytes: studies using the $\mathrm{Ca}^{2+}$-ATPase inhibitor thapsigargin," Experimental Cell Research, vol. 212, no. 1, pp. 84-92, 1994.

[27] P. Chattopadhyay, P. Chaudhury, and A. K. Wahi, "Ca+2 concentrations are key determinants of ischemia- reperfusioninduced apoptosis: significance for the molecular mechanism of Bcl-2 action," Applied Biochemistry and Biotechnology, vol. 160, no. 7, pp. 1968-1977, 2010.

[28] Y. Pu, K. Q. Luo, and D. C. Chang, "A $\mathrm{Ca}^{2+}$ signal is found upstream of cytochrome $\mathrm{c}$ release during apoptosis in HeLa cells," Biochemical and Biophysical Research Communications, vol. 299, no. 5, pp. 762-769, 2002.

[29] X. D. Liao, A. H. Tang, Q. Chen et al., "Role of $\mathrm{Ca}^{2+}$ signaling in initiation of stretch-induced apoptosis in neonatal heart cells," Biochemical and Biophysical Research Communications, vol. 310, no. 2, pp. 405-411, 2003.

[30] A. F. Chambers, A. C. Groom, and I. C. MacDonald, "Dissemination and growth of cancer cells in metastatic sites," Nature Reviews Cancer, vol. 2, no. 8, pp. 563-572, 2002.

[31] A. Schwab, B. Schuricht, P. Seeger, J. Reinhardt, and P. C. Dartsch, "Migration of transformed renal epithelial cells is regulated by $\mathrm{K}^{+}$channel modulation of actin cytoskeleton and cell volume," Pflügers Archiv, vol. 438, no. 3, pp. 330-337, 1999.
[32] H. Yamamura, S. Ugawa, T. Ueda, and S. Shimada, "Expression analysis of the epithelial $\mathrm{Na}+$ channel $\delta$ subunit in human melanoma G-361 cells," Biochemical and Biophysical Research Communications, vol. 366, no. 2, pp. 489-492, 2008.

[33] S. M. Del Mónaco, G. I. Marino, Y. A. Assef, A. E. Damiano, and B. A. Kotsias, "Cell migration in BeWo cells and the role of epithelial sodium channels," Journal of Membrane Biology, vol. 232, no. 1-3, pp. 1-13, 2009.

[34] G. I. Marino, Y. A. Assef, and B. A. Kotsias, "The migratory capacity of human trophoblastic BeWo cells: effects of aldosterone and the epithelial sodium channel," Journal of Membrane Biology, vol. 246, no. 3, pp. 243-255, 2013.

[35] Y. Yang, G. He, W. Xu, and X. Liu, "ENaC mediates human extravillous trophblast cell line (HTR8/SVneo) invasion by regulating levels of matrix metalloproteinase 2 (MMP2)," Placenta, vol. 36, no. 5, pp. 587-593, 2015.

[36] S. Wang, G. He, Y. Yang et al., "Reduced expression of Enac in Placenta tissues of patients with severe preeclampsia is related to compromised trophoblastic cell migration and invasion during pregnancy," PloS one, vol. 8, no. 8, article e72153, 2013.

[37] J. P. Warrington, K. Coleman, C. Skaggs et al., "Heme oxygenase- 1 promotes migration and $\beta$-epithelial $\mathrm{Na}^{+}$channel expression in cytotrophoblasts and ischemic placentas," American Journal of Physiology-Regulatory Integrative and Comparative Physiology, vol. 306, no. 9, pp. R641-R646, 2014.

[38] N. Kapoor, R. Bartoszewski, Y. J. Qadri et al., "Knockdown of ASIC1 and epithelial sodium channel subunits inhibits glioblastoma whole cell current and cell migration," The Journal of Biological Chemistry, vol. 284, no. 36, pp. 24526-24541, 2009.

[39] N. J. Ernest, A. K. Weaver, L. B. Van Duyn, and H. W. Sontheimer, "Relative contribution of chloride channels and transporters to regulatory volume decrease in human glioma cells," American Journal of Physiology-Cell Physiology, vol. 288, no. 6, pp. C1451-C1460, 2005.

[40] C. B. Ransom, J. T. O’Neal, and H. Sontheimer, "Volumeactivated chloride currents contribute to the resting conductance and invasive migration of human glioma cells," Journal of Neuroscience, vol. 21, no. 19, pp. 7674-7683, 2001.

[41] C. B. Ransom and H. Sontheimer, "BK channels in human glioma cells," Journal of Neurophysiology, vol. 85, no. 2, pp. 790803, 2001.

[42] L. Soroceanu, T. J. Manning Jr., and H. Sontheimer, "Modulation of glioma cell migration and invasion using $\mathrm{Cl}^{-}$and $\mathrm{K}^{+}$ion channel blockers," The Journal of Neuroscience, vol. 19, no. 14, pp. 5942-5954, 1999.

[43] K. Strange and R. Morrison, "Volume regulation during recovery from chronic hypertonicity in brain glial cells," American Journal of Physiology-Cell Physiology, vol. 263, no. 2, pp. C412C419, 1992.

[44] W. H. Vila-Carriles, G. G. Kovacs, B. Jovov et al., "Surface expression of ASIC2 inhibits the amiloride-sensitive current and migration of glioma cells," The Journal of Biological Chemistry, vol. 281, no. 28, pp. 19220-19232, 2006.

[45] A. K. Rooj, Z. Liu, C. M. McNicholas, and C. M. Fuller, "Physical and functional interactions between a glioma cation channel and integrin-betal require alpha-actinin," American Journal of Physiology-Cell Physiology, vol. 309, no. 5, pp. C308-C319, 2015.

[46] X. Sun, D. Zhao, Y.-L. Li et al., "Regulation of ASIC1 by $\mathrm{Ca}^{2+}$ / calmodulin-dependent protein kinase II in human glioblastoma multiforme," Oncology Reports, vol. 30, no. 6, pp. 2852-2858, 2013. 
[47] S. B. Ross, C. M. Fuller, J. K. Bubien, and D. J. Benos, "Amiloride-sensitive $\mathrm{Na}^{+}$channels contribute to regulatory volume increases in human glioma cells," American Journal of Physiology-Cell Physiology, vol. 293, no. 3, pp. C1181-C1185, 2007.

[48] J. Gao, B. Duan, D.-G. Wang et al., "Coupling between NMDA receptor and acid-sensing ion channel contributes to ischemic neuronal death," Neuron, vol. 48, no. 4, pp. 635-646, 2005.

[49] A. Bordey, H. Sontheimer, and J. Trouslard, "Muscarinic activation of BK channels induces membrane oscillations in glioma cells and leads to inhibition of cell migration," Journal of Membrane Biology, vol. 176, no. 1, pp. 31-40, 2000.

[50] R. Waldmann, "Proton-gated cation channels-neuronal acid sensors in the central and peripheral nervous system," Advances in Experimental Medicine and Biology, vol. 502, pp. 293-304, 2001.

[51] C. Jin, Q.-H. Ye, F.-L. Yuan et al., "Involvement of acid-sensing ion channel $1 \alpha$ in hepatic carcinoma cell migration and invasion," Tumor Biology, vol. 36, no. 6, pp. 4309-4317, 2015.

[52] E. K. Rofstad, B. Mathiesen, K. Kindem, and K. Galappathi, "Acidic extracellular pH promotes experimental metastasis of human melanoma cells in athymic nude mice," Cancer Research, vol. 66, no. 13, pp. 6699-6707, 2006.

[53] J. L. Wike-Hooley, J. Haveman, and H. S. Reinhold, "The relevance of tumour $\mathrm{pH}$ to the treatment of malignant disease," Radiotherapy and Oncology, vol. 2, no. 4, pp. 343-366, 1984.

[54] N. Shimokawa, I. Kumaki, C.-H. Qiu, Y. Ohmiya, K. Takayama, and N. Koibuchi, "Extracellular acidification enhances DNA binding activity of MafG-FosB heterodimer," Journal of Cellular Physiology, vol. 205, no. 1, pp. 77-85, 2005.

[55] H. L. Ji, C. M. Fuller, and D. J. Benos, "Osmotic pressure regulates alpha beta gamma-rENaC expressed in Xenopus oocytes," The American Journal of Physiology, vol. 275, no. 5, part 1, pp. C1182-C1190, 1998.

[56] R. Waldmann, G. Champigny, N. Voilley, I. Lauritzen, and M. Lazdunski, "The mammalian degenerin MDEG, an amiloridesensitive cation channel activated by mutations causing neurodegeneration in Caenorhabditis elegans," Journal of Biological Chemistry, vol. 271, no. 18, pp. 10433-10436, 1996.

[57] W. H. Vila-Carriles, Z.-H. Zhou, J. K. Bubien, C. M. Fuller, and D. J. Benos, "Participation of the chaperone Hsc70 in the trafficking and functional expression of ASIC2 in glioma cells," Journal of Biological Chemistry, vol. 282, no. 47, pp. 34381-34391, 2007.

[58] J.-H. Ye, J. Gao, Y.-N. Wu, Y.-J. Hu, C.-P. Zhang, and T.-L. Xu, "Identification of acid-sensing ion channels in adenoid cystic carcinomas," Biochemical and Biophysical Research Communications, vol. 355, no. 4, pp. 986-992, 2007.

[59] S. C. Grifoni, S. E. McKey, and H. A. Drummond, "Hsc70 regulates cell surface ASIC2 expression and vascular smooth muscle cell migration," American Journal of Physiology-Heart and Circulatory Physiology, vol. 294, no. 5, pp. H2022-H2030, 2008.

[60] X.-Y. Liu, S.-Z. Zhang, X.-Y. Ma et al., "Knockdown of ASIC2a subunit aggravates injury of rat C6 glioma cells in acidosis," Journal of Physiology and Biochemistry, vol. 67, no. 2, pp. 275281, 2011.

[61] M. Assmann, A. Kuhn, S. Dürrnagel, T. W. Holstein, and S. Gründer, "The comprehensive analysis of DEG/ENaC subunits in Hydra reveals a large variety of peptide-gated channels, potentially involved in neuromuscular transmission," $B M C$ Biology, vol. 12, article 84, 2014.
[62] S. C. Gupta, R. Singh, M. Asters et al., "Regulation of breast tumorigenesis through acid sensors," Oncogene, 2015.

[63] S. Amara, M. T. Ivy, E. L. Myles, and V. Tiriveedhi, "Sodium channel $\gamma \mathrm{ENaC}$ mediates IL-17 synergized high salt induced inflammatory stress in breast cancer cells," Cellular Immunology, vol. 302, pp. 1-10, 2016.

[64] M. Damaghi, J. W. Wojtkowiak, and R. J. Gillies, "pH sensing and regulation in cancer," Frontiers in Physiology, vol. 4, article 370, 2013.

[65] L. Schaefer, H. Sakai, M.-G. Mattei, M. Lazdunski, and E. Lingueglia, "Molecular cloning, functional expression and chromosomal localization of an amiloride-sensitive $\mathrm{Na}^{+}$channel from human small intestine," FEBS Letters, vol. 471, no. 2-3, pp. 205-210, 2000. 


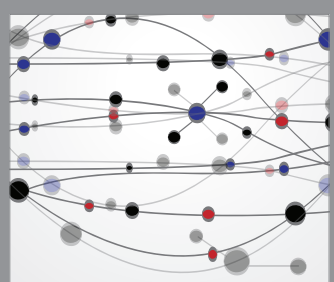

The Scientific World Journal
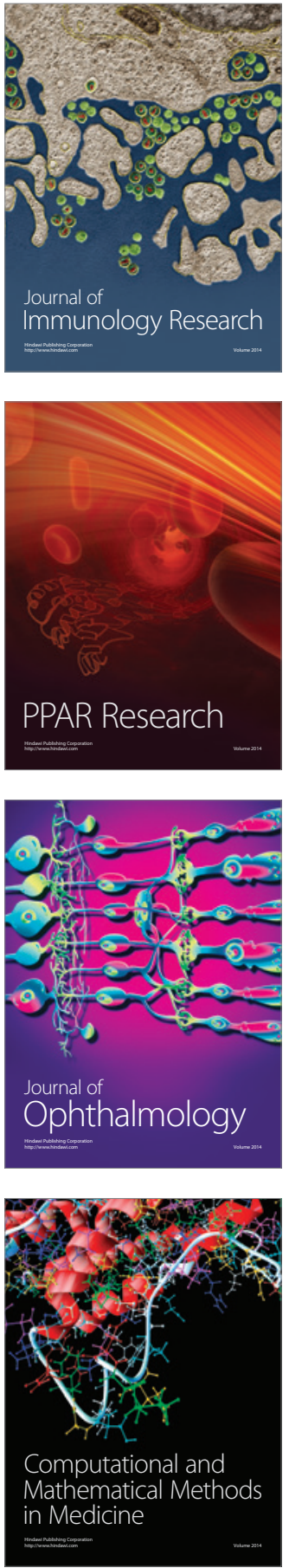

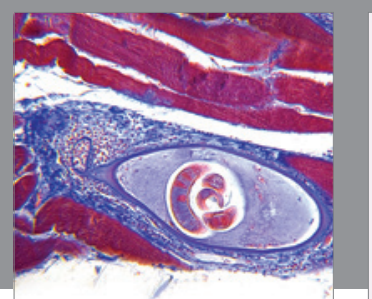

Gastroenterology Research and Practice

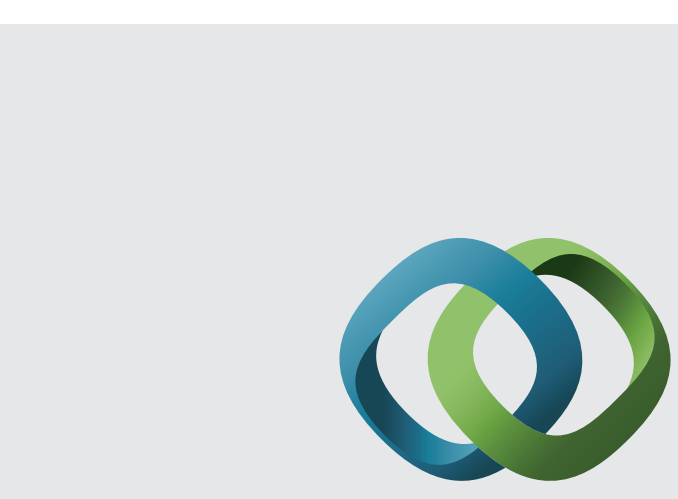

\section{Hindawi}

Submit your manuscripts at

http://www.hindawi.com
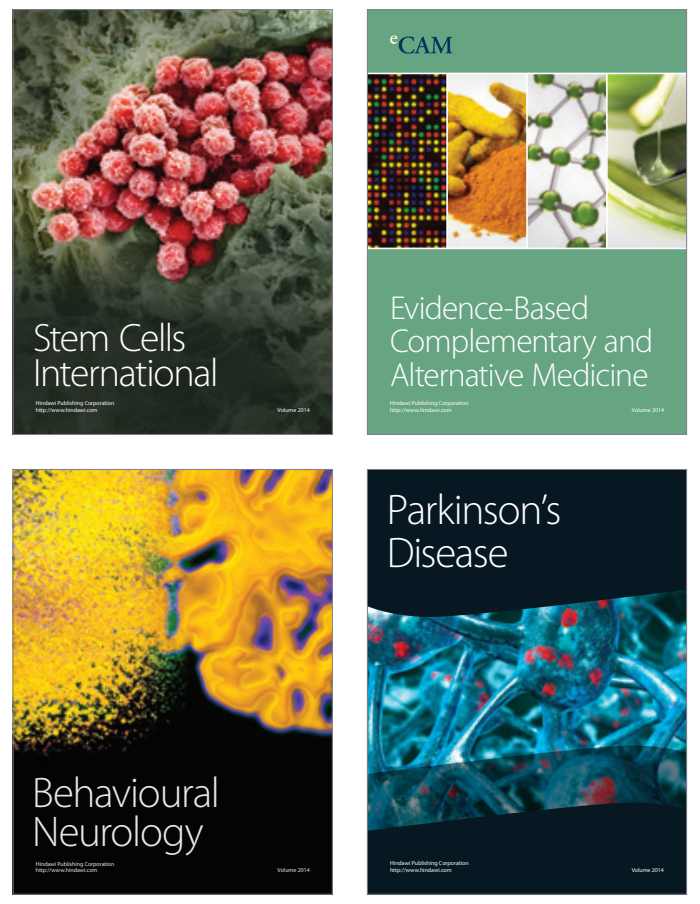
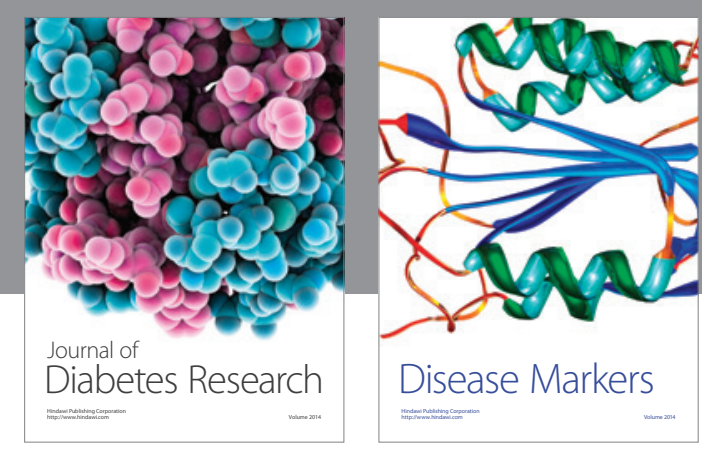

Disease Markers
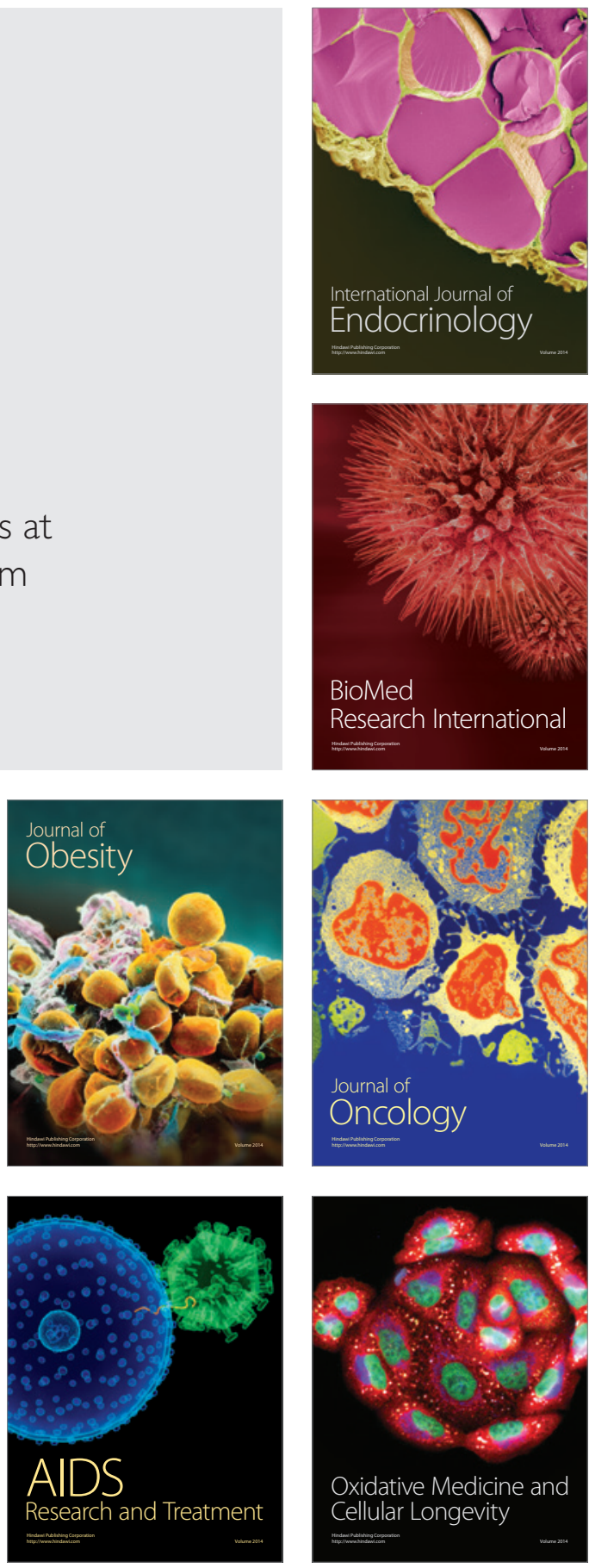